\title{
LA LITERATURA INFANTIL EN ESPAÑA Y EN EL MUNDO ÁRABE: LA FUNCIÓN DIDÁCTICA Y LINGÜÍSTICA DEL CUENTO EN ESPAÑA Y JORDANIA
}

\author{
CHILDREN'S LITERATURE IN SPAIN AND IN THE ARAB WORLD: THE \\ DIDACTIC AND LINGUISTIC FUNCTION OF THE TALE IN SPAIN AND JORDAN
}

Ahmad Husein Al-Afif

Ziyad Mohammad Gogazeh

Ahmad Al-Meshref Al-Harahsheh

Universidad de Jordania

\section{RESUMEN:}

En este estudio comparativo entre España y el mundo árabe, concretamente Jordania, se analizarán las funciones didácticas de los cuentos para niños. Este estudio se ha realizado a partir de encuestas para conocer la influencia y la importancia de este tipo de literatura infantil en la educación de los niños.

\section{Palabras claves:}

Cuento, niño, árabe.

\section{Abstract:}

In this comparative study between Spain and the Arab world, concretely Jordan, the didactic functions of tales will be analysed. This study has been carried out with surveys in order to know the influence and the importance of this kind of children's literature on child's education.

\section{KEY WORD:}

Tale, child, Arab. 


\section{INTRODUCCIón}

Muchos son los estudios que se han escrito sobre el tema de la literatura infantil, pero son muy pocos los estudios comparativos entre España y el mundo árabe. En este artículo intentamos arrojar luz sobre la función didáctica de los cuentos en los dos países, España y Jordania. Habrá una parte teórica que enfoca sobre las fuentes principales de los cuentos en ambos países, teniendo en cuenta las formaciones socioculturales que representan la mayor diferencia entre las dos culturas.

Antes de meternos en el tema de nuestra investigación actual convendría arrojar luz sobre el estado del niño árabe tanto como el español respeto a este género literario.

\section{LA REPERCUSIÓN DE LA LITERATURA INFANTIL AL PÚBLICO INFANTIL EN \\ EL MUNDO ÁRABE Y ESPAÑA}

Para que entendamos mejor la repercusión del contenido de la literatura infantil al pensamiento y la información del niño árabe tanto como aquel del español ha de reconocer que estamos ante dos públicos pertenecientes a dos espacios y mundos culturales distintos que tienen sus propias peculiaridades y sus propias personalidades culturales, por lo cual se surgían antes llamamientos que pedían géneros literarios que muevan dentro del marco cultural de cada nación, es decir géneros literarios inspirados del bagaje cultural de cada público al que se dirige. Esos llamamientos siempre han tenido sus teorizantes y sus pros en el mundo islámico, partiendo de la ideología que llama a la conservación de la identidad cultural y dogmática del niño.

\section{EL NIÑO ÁRABE Y ESPAÑOL Y LA UNIVERSALIZACIÓN DE LA LITERATURA} INFANTIL

Lo que nos interesa en este contexto es la literatura árabe infantil moderna, y para comprenderla bien ha de aclarar cómo evolucionó y como llegó a ser lo que lo es hoy día. A través de la encuesta que hemos hecho a los dos públicos encuestados (La encuesta se apoyó en un grupo de estudiantes del departamento de lenguas europeas/ Facultad de Lenguas en la universidad de Jordania y otro del Departamento de lenguas integradas de la universidad de Sevilla/ Facultad de Filología/ España. ), hemos encontrado que la mayoría de los cuentos y fabulas que tienen presencia entre los niños árabes son clasificados bajo el género de la literatura infantil universal y llevan en su contenido principios y ideologías morales que contradicen con aquellos a los que se creció el niño.

El mundo árabe siempre ha sido sujeto a tribulaciones que iban siempre dejando unas huellas en su identidad cultural, ya que después del caída de Granad en 1492, el mundo árabe iba cambiándose de una nación exportadora del conocimiento a una importadora y consumidora de lo que hace el otro, concretamente me refiero aquí por el otro a la Europa durante el siglos diecinueve y veinte y a Estados unidos a partir de la segunda mitad del siglo veinte y la primera del siglo veinte uno.

La entrada de los cuentos y fabulas universales en la literatura árabe moderna empezó después de la aparición de Al-Nahda, (renacimiento) que es un movimiento que llamaba a la reforma cultural e intelectual que surgió como una reacción a las malas condiciones y decadencia que vivía el mundo árabe de aquel entonces, este movimiento duró desde los comienzos del siglo XIX hasta los comienzos del siglo XX

El renacimiento árabe vino acompañado con un movimiento traductor serio que empezó por la traducción de obras de la literatura europea y concretamente la francesa por un grupo de eruditos y traductores que recibieron su formación académica en Francia y cuyo pionero fue Rifaa al-Tahtawi. Al-Tahtawi encabezó esta escuela de traducción y fundó la Facultad de Lenguas en Egipto en 1835, y junto a sus alumnos tradujeron más de dos mil libros en todas las ramas de las ciencias (Rajab, Sawsan, Asr al-Nahda, http://www.angelfire.com/nd/prose/nahda.htm).

Más tarde la literatura infantil era uno de los géneros literario que sometieron a este movimiento traductor y empezaron a aparecer en el mundo árabe fabulas y cuentos que conllevan con si, principios e ideologías ajenas y poco a poco iban arraigándose en la conciencia y la formación del niño árabe. Estas nuevas ideologías empezaron a tomar más difusión y más influencia después del llamado la Globalización ola americanización que trajo consigo más cuentos y fabulas infantiles de distintas culturales y diferentes orígenes. Este caos cultural hizo al niño árabe vivir unas contradicciones y paradojas culturales porque algunas de las morales y principios que lee en los cuentos de hoy día contradicen con lo que se le enseñó desde su niñez, hecho que a veces le hace vivir una esquizofrenia cultural, ya que uno de los encuestados jordanos pone lo siguiente en la encuesta que hicimos a dos grupos de estudiantes, jordanos y españoles

(Siempre desde que he sido niño se me enseñaba en el colegio, la calle, la familia y en todos los sitios, que no se puede besar a una niña ajena porque es un hecho que contradice con la religión y la cultura social, pero un día tomé prestado de la biblioteca de mi colegio el cuento Blancanieves, eso cuando tenía doce años, y me quedé mucho pensando cuando leí lo siguiente:

En aquel momento apareció un príncipe a lomos de un brioso corcel y nada más contemplar a Blancanieves quedó prendado de ella. Quiso despedirse besándola y de repente, Blancanieves volvió a la vida, pues el beso de amor que le había dado el príncipe rompió el hechizo de la malvada reina.)

En cuanto al niño árabe de hoy día podemos clasificar la literatura infantil que se dirige a él en dos clases: 


\section{1 - La literatura infantil inspirada de la cultura madre.}

\section{2 - La literatura infantil inspirada de la cultura ajena.}

La primera clase no representa ningún problema o paradoja y a ojos de algunos influye positivamente en la identidad cultural del niño árabe porque está inspirada de su cultura, dogma, forma de pensar etc..y desempeña un papel importantísimo en arraigar los principios y fundamentos de su identidad cultural y dogmática a través del texto. La segunda clase como ya se ha quedado claro arriba puede arrastrar al niño árabe a contradicciones y paradojas inadecuadas.

En cuanto al niño español no ha pasado por estas tribulaciones de identidad de las que padecía el niño árabe porque la literatura infantil que se dirige a él, no contradice con su bagaje cultual, incluso la literatura importada del otro o la ajena como la hemos llamada antes no va lejos de la suya porque si coge algo de la cultura francesa o italiana es al fin y al cabo europea y tampoco la norte americana va lejos de la suya, y es bien sabido que la mayoría de los cuentos que se hicieron universales son europeas o norteamericanas.

\section{LA LITERATURA INFANTIL, DEFINICIÓN E HISTORIA}

Como es bien sabido, la literatura infantil es uno de los géneros literarios renovados en el mundo, aunque ya existían los cuentos de las madres, pero todo fue transmitido de forma oral. Su importancia surgió en la literatura universal desde hace pocos siglos, pero podemos decir que los verdaderos estudios de los términos "niñez" y "literatura infantil" comenzaron durante finales del siglo XIX y comienzos del siglo XX (Moctezuma, 2002: 339), es decir, es un movimiento coetáneo al Modernismo.

La literatura infantil, como cualquier otro tipo de literatura, forma parte de la literatura universal pero se dirige a una clase de lectores y espectadores inmaduros, y esta clase representa en algunos países más de la tercera parte de su población. Nancy Anderson define la literatura infantil como: todos los libros escritos para los niños, excepto aquellos libros que llevan cómics, chistes, y los libros que no se escriben para ser leídos en su momento, como por ejemplo los diccionarios, las enciclopedias, y cualquier material de referencia (Anderson, 2006: 2)

Este tipo de literatura es diferente de los demás tipos porque la compresión de sus receptores está relacionada con escasa experiencia en la vida, y por lo tanto, su consciencia es totalmente diferente a la de los adolescentes (Abu Ma'al, 1988: 12).

Como hemos mencionado antes, los niños forman un gran número de la población, y cuando escribimos alguna obra literaria dirigida a los niños estamos tratando un sector fundamental en la sociedad, por ello, escribir para esta categoría necesita mucho cuidado de parte del escritor porque todo lo que lee el niño afecta positiva o negativamente la formación de su mentalidad, y todo aparecerá en su madurez. Así, hay que clasificar las obras que se dirigen a los niños y pasarlas por la censura antes de publicarlas y difundirlas.

La importancia de este género literario surge en varios aspectos, pero sobre todo el aspecto didáctico. La literatura infantil, por un lado, enseña al niño los problemas de su sociedad, además le enseña su lengua materna a través de leer los cuentos y las historias. Por otro lado, este tipo de literatura abre la mente del niño y le hace pensar en las cuestiones filosóficas de nuestro mundo.

Ahora bien, nos surge una pregunta: ¿Por qué no hay mucha documentación a la literatura infantil, sobre todo a los cuentos antiguos?

Ha de saber que este tipo de literatura es muy antiguo, quizás tan antiguo como la literatura dirigida a los adultos, pero en mayoría fue transmitida de una generación a otra oralmente. Las madres suelen contar algunas historias o cuentos a sus niños antes de dormir, y no se darían cuenta de que esta etapa es la más importante en la vida de sus niños y deberían tratar a sus hijos de forma más seria. Muchos padres pensaban que el niño no entiende las historias que les cuentan, sin embargo, los niños recuerdan siempre las primeras historias que han escuchado durante su infancia. Pero, a partir del siglo XVIII la gente comenzó a escribir la literatura infantil en libros (AlHadid,1982: 38)

La literatura infantil en España tiene poca experiencia (referimos a qui a la literatura escrita). Desde finales del siglo XIX no había más que la literatura hablada, excepto algunas obras que fueron escritas con el propósito de moralizar a los niños y a los jóvenes en general (Rodríguez, 2000: 50). Dos de las excepciones fueron los autores Padre Coloma y Fernán Caballero. Un poco más tarde, la literatura infantil europea fue transmitida a España a través de la traducción. Los libros del danés Hans Christian Anderson, por ejemplo, fueron traducidos al castellano durante los años sesenta del siglo XIX (Pérez, 2000: 76). Más tarde, otras obras, sobre todo de origen francés, fueron traducidas al castellano también, y por eso, se nota que hay una influencia francesa en la literatura infantil española.

\section{OBJETIVOS DE LA LITERATURA INFANTIL: IDEOLOGÍA Y DIDÁCTICA}

Cuando escribimos literatura dirigida a los niños, se debe pensar en el tema de identificarse en la sociedad. Para que los niños se identifiquen con el mundo que les rodea, apreciar las diferencias y las semejanzas de los demás, y así mismos, es importante que el niño descubra su propia identidad. Proveer los niños con literatura es una manera para ayudarles a alcanzar este sentido de identidad. Los libros con personajes de fondos similares, o aquellos con situaciones familiares para los niños 
sirven como herramientas muy útiles para guiar a los niños a descubrir su identidad y su importancia en sus comunidades, que forma parte de la gran sociedad, y es la manera de transmitir la historia de esta sociedad a los niños. A veces los niños se identifiquen a través los personajes de los cuentos que leen (Revista Enlace, "Libros para niños: para soñar un mundo diferente", Enlace no.83.,http://www.simas.org.ni/ revistaenlace/articulo/806); los niños relacionan las historias de los personajes con sus propias historias, y esto les puede ayudar a solucionar sus problemas, viendo como las situaciones y las circunstancias tratadas por los demás. Estos cuentos pueden también inspirar a los niños que persigan metas porque alguien como ellos hizo lo mismo. La familia, la vida casera y las situaciones culturales, junto con las formas de la vida, varían con diversos grupos étnicos. Los niños deben encontrar los cuentos que se centran en sus identidades étnicas y fondos para ayudarles a desarrollar su consciencia de su existencia como ser humano, y al mismo tiempo es importante que el niño crezca con estas ideas, y así puede lograr la valoración de los demás.

\section{EL DESARROLLO DE LA LITERATURA INFANTIL EN ESPAÑA}

Son cercanas las fechas en las que este género literario empezó a aparecer en España y el Mundo árabe. Como ya se ha dicho antes este género apareció en el mundo árabe en la mitad del siglo dieciocho y específicamente en Egipto durante la época de Mohammad Ali, donde Rifaa al-Tahtawi tradujo Hikayat al Tafal (los cuentos de los niños) y Oklat al Usba del francés al árabe, y fue él el primero que introdujo este género literario en los métodos didácticos en Egipto (Suleiman, Tarij Tatwwor Adab alAtfal Arabian wa Alamian, http://www.adabatfal.com).

En cuanto a España, La narrativa basada sobre la realidad con niños protagonistas y sin ninguna intención didáctica apareció en España en los años veinte del siglo XX (Monografías sobre la literatura infantil, Portal Alipso.com http://www.alipso.com/ monografias/literaturainfantil, 2000:4). El ambiente en el que vivían aquellos niños representaba la clase media y la clase alta, y es el caso de la obra Celia, que fue una serie criada por Elena Fortín (Padrino, 2001: 65)

Después de la Guerra Civil, el gobierno de la dictadura dio un impulso a los libros escritas para los niños. Los temas más preferidos fueron básicamente fantásticos y heroicos; estos temas fueron inspirados de la literatura clásica y de la literatura folclórica española. Mencionamos algunos nombres de escritores de la literatura infantil de los años cincuenta como José María Sánchez Silva, Joaquín Aguirre Bellver (Instituto de Cultura Hispánica (Spain), 1981: 372 y 733) , entre otros.

Durante los años sesenta, aparecen los temas más reales y problemáticos en la literatura infantil, sobre todo, los temas de los inmigrantes. Es muy importante señalar aquí que, antes de 1962 estaba prohibido escribir libros para niños en otra lengua más que el castellano. Pero, más tarde, se escribía en otras lenguas, sobre todo en catalán (Villasante, 1979: 45).

\section{EL NOBLE CORÁN: RECURSO BÁSICO DE LOS CUENTOS EN LA LITERATURA} INFANTIL ÁRABE

En casi todas las "soras" del Noble Corán existen cuentos y moralejas que pueden ser un buen recurso didáctico, sobre todo para los niños musulmanes árabes. Las historias se tratan de la lucha entre el bien y el mal. Según Sheik Amin Bakri, las historias en el Corán tienen todos los componentes del cuento o la historia normal: personajes, diálogo, lugar, tiempo, clímax y desenlace final (Bakri, 1976:67).

Los escritores de los cuentos infantiles aprovecharon las historias del Noble Corán en dos maneras: la primera se trata de que la mayor parte de las historias mencionadas en el Sagrado Corán se ha reescrito para los niños en una lengua y estilo adecuados para su edad. La segunda se trata de que la mayor parte de las historias muestren la lucha entre el bien y el mal, y al final siempre hay una moraleja (Mdallel, , Vol.8, № 2: 2004). Por lo tanto, vemos que los cuentos destacados del Sagrado Corán enfocan sobre la moralidad, a través de la prohibición de las acciones incorrectas y la imposición de las correctas.

\section{LA IMPORTANCIA DE NARRAR CUENTOS A LOS NIÑOS}

Cuando hablamos de la importancia de los cuentos en el mundo árabe eso no quiere decir que es tan diferente en el mundo occidental, sobre todo en España. Son muchas las ventajas contar cuentos y una de ellas es ampliar la imaginación del niño: el niño empieza en los primeros años de su infancia a formar en su imaginación las acciones del cuento y así puede tener buena memoria y habilidad de imaginar las cosas en su vida cotidiana cuando crece.

Otra ventaja es formar una base de conocimiento para el niño, y así podemos notar que el niño que escucha o lee cuentos sabe más que sus iguales que no escuchan o leen cuentos. Este conocimiento viene a través de las informaciones que el niño adquiere de las historias y las acciones de los cuentos (Julieta La Rotonda http://mariaauxiliadora. idoneos.com/index.php/Nivel Terciario/Actividad academica/Producciones de los alumnos/Valores en el cuento infantil)

Una tercera ventaja es enseñar al niño la pronunciación correcta de las letras. Como es bien sabido, el niño imita los sonidos que oye de sus padres o de la gente que le rodea por lo tanto, contar una historia antes de dormir o durante el día tiene su efecto positivo en ayudar al niño a tener buena articulación a las letras (Remigio Jara y otros, № 32223, 2007: http://webcache.googleusercontent.com/search?q=cache:B9 5xT5mUHs]:www. slideshare.net/kajol12/ 
Podemos añadir también que este proceso enriquece el diccionario léxico del niño y le ayuda a expresarse utilizando las palabras aprendidas, y en este caso mencionamos un estudio que hemos hecho en Jordania sobre una muestra de niños que escuchaban cuentos contados en árabe clásico por sus padres. El resultado ha sido sorprendente; los niños entre tres a ocho años han podido mantener unas conversaciones breves con sus padres utilizando el árabe clásico en vez del árabe dialectal, y la consecuencia es tener niños preparados para aprender su lengua materna antes de recibir su enseñanza en el colegio (Hemos realizado un estudio de campo en el público infantil en Jordania y hemos llegado a los resultados mencionados a través de escoger muestras de las edades de los niños de Jordania).

Otra ventaja de contar cuentos a los niños es enseñar al niño la forma correcta de hace un diálogo a través de respetar las opiniones de los demás y soltar la energía guardada en él (Caduto, 1993:45). Muchos expertos en los asuntos infantiles y pedagogos apoyan la idea de participación del niño en contar la historia a través de recontarla o utilizar los gestos y los mimos, imitando a los personajes, sean seres humanos o animales, y esto ayuda mucho a formar buenas cualidades en el carácter del niño, como la valentía y ser muy sociable, etc....

Y aún hay muchas ventajas en contar los cuentos a los niños pero no cabe mencionarlas todas en este sentido.

Hemos realizado un estudio en el campo de la sociedad infantil en Jordania y hemos llegado a dividir los cuentos a varios tipos según la edad del niño. Por ejemplo, las fábulas y los cuentos cortos son más adecuados para niños entre dos y cinco o seis años. Sin embargo, los cuentos de aventuras y las leyendas son más apropiados a los niños entre siete y doce años. Para los niños mayores de doce años ya pueden leer o escuchar los cuentos más bien largos y podrían ser novelas o historias reales o importantes en la cultura de su país, como es el caso de leer los cuentos de Las mil y una noches, por ejemplo.

Los cuentos de hoy día están en peligro por el uso de la nueva tecnología como el televisor y el ordenador. Las madres ya no cuentan a sus niños de Shahrazad y Aladino como antes sino les dejan jugar con los juegos del ordenador hasta que se queden muy cansados y dormidos. La desaparición del elemento narrativo para el niño tiene sus malas consecuencias como la recepción de malas expresiones o palabras que los niños escuchan en las noticias de la televisión o actuar en forma violenta con los demás después de ver los juegos del ordenador que tratan los temas de las batallas y las peleas, entre otros juegos violentos. Es muy necesario que la madre use la nueva tecnología en enseñar a su niño, pero no tiene que olvidar que la narración de los cuentos es muy importante, y a pesar de que haya narraciones a través de los ordenadores, la narración personal de un cuento de la madre a su niño es más útil, sobre todo la narración antes de dormir porque el niño siente el cariño de su madre junto con las palabras que ella articula con su propia voz.

La literatura infantil en España ha pasado por obstáculos (Melero, 2001: 105), tanto como en el Mundo Árabe. Esto debido a las guerras y las épocas de decadencia que han pasado los españoles y los árabes. Mencionamos por ejemplo las épocas de la decadencia en España durante los siglos XVII y XVIII que tuvieron muy poca literatura dirigida a los niños (Borque, 1975: 312), a pesar de producir obras literarias por famosos, como Lope de Vega, Calderón de la Barca, Francisco de Quevedo, etc.... Por otro lado, el Mundo Árabe vivía durante la misma época bajo el dominio otomano y la producción literaria en general fue muy escasa. Esta situación de decadencia y ambiente lleno de guerras acompañó a los pueblos (árabes y españoles) hasta el siglo XX. Las generaciones de los niños de los siglos anteriores a este siglo fueron obligados a leer u oír las historias y los cuentos de los héroes de su época; en España se leían las novelas como El Quijote de Cervantes y El Buscón de Quevedo, y otros cuentos que representaban libros de caballerías y exaltación a los héroes y a la patria. Al mismo tiempo, había algunos cuentos en el mundo árabe que se consideraban leyendas de varios origines más que el árabe, como las leyendas de Shahrazad y algunos cuentos de origen indio y persa. Todos estos cuentos se consideran cuentos para adultos, pero la falta de la literatura infantil obligó a los padres a contarlos a sus hijos, y el resultado fue encontrar a unas generaciones llenas de desesperación por tanto leer y escuchar historias con temas serios llenos de miedo frustración.

Más tarde, durante el siglo XX, en una época tardía después de la primera mitad de siglo y después de la salida de los otomanos seguidos por los ingleses y los franceses del Mundo Árabe, y después de la Guerra Civil en España, ambos pueblos empezaron a establecer la literatura infantil basada sobre las nuevas teorías de la educación. La consecuencia ha sido la apertura de nuevos horizontes dirigidos a la escritura para el niño con objetivos didácticos.

Contar los cuentos es muy importante en el aprendizaje del niño. Muchos psicólogos han afirmado que contar historias o cuentos de temas violentos afecta negativamente la imaginación del niño y produce reacciones semejantes de parte del niño en el futuro. Además, contar historias de ciencia ficción puede causar la muerte de algún niño; mencionamos en este sentido el caso de un niño de la ciudad de Amman que se arrojó del balcón de su casa en el sexto piso del edificio pensando en los saltos que hacía Spiderman; y se murió en el acto.

Un caso parecido ocurrió en un pueblo de España, pero esta vez el niño iba con el traje de Superman y pensaba que así podrá volar después de hacer un salto de un puente. 
Hay más accidentes de este tipo que ocurrieron con niños después de escuchar algunos cuentos violentos y ficticios, tanto en España como en Jordania, y eso es debido a la mala elección que hacen los padres al elegir los cuentos para contar a sus niños.

Hemos realizado una encuesta en España y Jordania que trata de preguntar una muestra de ambas sociedades algunas preguntas relacionadas con su infancia y los cuentos que solían escuchar o leer.

Una de las preguntas fue sobre los títulos de los cuentos que leyó o escuchó el encuestado durante su infancia. Las respuestas de esta pregunta nos sorprendió mucho por dos motivos: muchos de los cuentos de abuelas contados en España y en Jordania siguen siendo contados hasta hoy, a pesar de que haya algunas modificaciones en las narraciones. El otro motivo es que algunos cuentos se narran en ambos países con muy pocas diferencias; es decir, tienen la misma historia pero se narran en dos lenguas distintas: el castellano y el árabe. Además, algunos cuentos que se cuentan en España tienen las mismas acciones que otros cuentos que se cuentan en Jordania pero con la diferencia en el título del cuento. Hay muchos cuentos que representan buenos ejemplos de esta diferencia como el cuento de Blanca Nieves en la versión castellana que equivale Bayad Ath-thaldj en la versión árabe. Otro ejemplo es el cuento Pinocho en la versión castellana que equivale Madjed en la versión árabe.

Esta semejanza puede ser debida al movimiento de traducción en todo el mundo y muchos traductores en el mundo tradujeron obras maestras de autores celebres, y otros tradujeron los cuentos, sobre todo durante los siglos XIX y XX, debido a la demanda de crear la literatura infantil con su sentido moderno durante aquella época (Etxaniz, Revista de psicodidáctica, 2008, vol. 13, № 2.: 98).

Otra pregunta que hemos preguntado a los encuestados fue sobre el cuento que le gustó y también sobre la influencia de este cuento en su vida, sea positiva o negativa. La respuesta de esta pregunta nos sirvió de hacer un análisis psicológico de la influencia de los cuentos en la vida de los niños y sus recuerdos cuando crezcan y sean mayores. En España, el cuento más favorito fue María por ser pobrecita ante su hermano que se reía de ella porque no sabía leer ni escribir y ignoraba muchas cosas que su hermano sabía. Sin embargo, ella sabía algunas cosas que él ignoraba, aunque eran cosas de poca importancia, pero quiere decir que cada cual tiene su conocimiento o "mundo ideal" y no debe burlarse de los demás porque pueden saber más. En cambio, en Jordania, el cuento más favorito fue la serie de cuentos de Yehá o Yuh:a, y este personaje es cómico pero al mismo tiempo es sabio y siempre en sus cuentos aparte de la risa que se produce al lector se saca una moraleja. Esta serie de cuento puede ser una de los cuentos más antiguos en la historia de la literatura infantil árabe y han sido contados al lo largo de las generaciones.
Hemos preguntado los encuestados sobre sus gustos de los temas de los cuentos y si los cuentos religiosos tenían tanta influencia en la formación de su imaginación. Hemos encontrado que la mayoría de los encuestados aprecian los cuentos relacionados con el tema religioso. En España, por un lado, muchos de los encuestados apreciaban escuchar los cuentos de la Virgen y su Hijo, Jesucristo. Además, vivían las historias de estos cuentos en forma anual en la actuación de estas historias durante la Semana Santa. Por otro lado, los encuestados en Jordania demostraron su valoración y gusto a los cuentos relacionados con el Sagrado Corán y el generoso profeta Mohammad, que solían escuchar en su infancia.

\section{CONCLUSIÓN}

Después de este breve estudio comparativo podemos concluir algunas cosas muy importantes cunando tratamos la sociedad infantil. Una de estas conclusiones se trata de la historia de la literatura infantil en España y en el mundo árabe: podemos decir que en ambos mundos (y en Jordania específicamente) este género ha sido nuevo, a pesar de encontrar algunas obras que servían como libros dirigidos al público infantil, pero hay que señalar que la importancia de escribir un tipo de literatura especial para los niños surgió hace poco tiempo.

A pesar de las diferencias socio-culturales de ambos mundos pero los niños piensan en la misma manera y siempre esperan alguien que les cuente alguna historia o cuento antes de dormir. Quizás haya algunas diferencias en las maneras de contar las historias según los padres en ambos mundos, pero al final los padres tienen que volver a la manera tradicional de contar las historias a sus hijos en forma directa.

La literatura infantil es una de los medios didácticos que enseñan los niños tanto en España como en el mundo árabe, sobre todo en Jordania donde hicimos una encuesta sobre este mismo tema. Los cuentos pueden afectar la mente del niño en forma positiva o negativa según la calidad de la historia y la existencia de alguna lección o moraleja. Por ese motivo hay muchas historias en España y en Jordania derivadas de la Biblia y del Sagrado Corán.

\section{REFERENCIAS BIBLIOGRÁFICAS}

Abu Ma'al,Abdelfattah, Adab Al-'atfal, Dar Al-Shoroq, Amman, 1988.

A. Castro, C., Clásicos de la literatura infantil, Editorial Lex nova, Valladolid, España, 1984.

Al-'as 'ad, Omar, Adab Al-'at:fal, 'alam al-kotob al-h:adith, Irbid, 2003, Al-ordon.

Al-Hadid, Ali, Fi Adab Al-'Atfal, Maktabat Al-Anglo Al-Mesreyah, Al-Qaherah,1982. Anderson, Nancy, Elementary Childeren's Literature, Pearson Educaction, Boston, 2006. 
Arconada Melero, M. Á. y Fuertes Ramos, C., Destrezas comunicativas en la lengua española, Ilustrado, Ministerio de Educación, 2001.

Bakhtin, M.M, The Dialogic Imagination, Austin: University of Texas Press, 1981.

Bakri, Sheik Amin, At-ta'bir Al-Fanni fi Al-Korán (La expresión artística en el Corán), Dar Ash-Shuruq, Beirut, 1976.

Bravo-Villasante, C., Antología de la literatura infantil en lengua española, Doncel, Madrid, España, 1973.

-----, Historia de la literatura infantil española, Editorial Escuela Española, Madrid,1979.

Díez Borque, J. M., Historia de la literatura español: siglos XVII y XVIII, Biblioteca Universitaria Guadiana, p.312.

Dobles Rodríguez, M., Literatura infantil, Editorial EUNED, Costa Rica, 2000.

Domínguez Pérez, M., Las traducciones de literatura infantil y juvenil en el interior de la comunidad interliteraria específica española (1940-1980), Universidad de Santiago de Compostela, España, 2000

Etxaniz, X., "Investigación en torno a la literatura infantil y juvenil", Revista de psicodidáctica, El País Vasco, Año 2008, vol. 13, № 2.

García Padrino, J., Así pasaron los años: en torno a la literatura infantil, Universidad de Castilla la Mancha, España, 2001.

H., Inani, Adab Et-tifl (Literatura del niño), Amman: Dar Al-Fikr. 1999 H:alawah, Mohammad Al-Sayyed, Kotob wa maktabat al-át:fal, Maktabat bostan al ma`refah, Al-eskandareyah, 2007.

Instituto deCultura Hispánica (Spain), Centro Iberoamericano deCooperación, Instituto de Cooperación Iberoamericana, Cuadernos Hispanoamericanos: volúmenes 376378, Ediciones Cultura Hispánica, Madrid, Spain, 1981.

J. Caduto, M., Guía para la enseñanza de valores ambientales, Los libros de la Catarata, Bilbao, España, 1993

Jara, Remigio,y otros, “La narración de cuentos como estrategia en el desarrollo de la expresión oral en los niños y niñas de segundo grado de la I.E.", Instituto de formación docente, № 32223, PERÚ, 2007. http://webcache.googleusercontent.com/ search?q=cache:B9_5xT5mUHsJ:www.slideshare.net/kajol12/

Lluch, G. (coordinadora del libro), La invención de una tradición literaria: De la narrativa oral a la literatura para niños, Arcadia, Universidad de Castilla la Mancha, España, 2007.

Machado, A. M. y Montes, G., Literatura infantil: creación, censura y resistencia, Editorial Sudamericana, Buenos Aires, Argentina, 2003.

Mdallel, S., "The sociology of childre's literature in the Arab World", Vol.8, № 2, 2004
Malas, Mohammad Bassam, Kotob Al-'at:fal Al-mos:awarah, wazarat ath-thaqafah Amman, 1989.

Martínez Moctezuma, L., La infancia y la cultura escrita, Ilustrado, Educación (Mexico City, Mexico), 2002.

Mohammad al-Fadil Suleiman, Tarij Tatwwor Adab alAtfal Arabian wa Alamian http://www.adabatfal.com

Moreno Verdulla, A., Literatura infantil: introducción en su problemática, su historia y su didáctica, Servicio Publicaciones Universidad de Cádiz, España, 1988.

Musa, Abdelmo 'ty Nemr, Adab al-'atfal, Dar Al-Kindy, Irbid, 2000.

Nadjyb,Ahmad, Al-Madmu:n fy kitab al-'atfa:l, Dar al fekr al-'araby, Al-qahirah, Masr, 1979.

Riitta, O., Translating for Children, New York and London: Garland Publishing, 2000. Rajab, Sawsan, Asr al-Nahda, http://www.angelfire.com/nd/prose/nahda.htm

Sa id, Mahmoud Shaker, 'Asaseyat fi adab al-atfal, Dar al-ma aredj al-dawleyah Al-reyad, 1993. La Rotonda, Julieta, "Valores en el cuento infantil", http://mariaauxiliadora.idoneos.com/index.php/Nivel

Terciario/Actividad_academica/Producciones_de_los_alumnos/Valores_en_el_ cuento infantil 